\title{
Supporting the Child During the Wake-Up Time
}

\author{
Dane S. Hughes* \\ Children's Psychiatric Hospital \\ University of Michigan
}

Waking up is, for all of us, a time of restructuring our perception of reality, organizing our defense mechanisms toward coping, mobilizing the ego to engage the world - i.e., "getting our heads together." This is a task we face and deal with daily throughout our lives, and which we all occasionally find difficult. With the children we serve, it is difficult more often than not. As Brown (1972) suggests,

For emotionally disturbed children, however, the coming day holds little promise of anything good. For them, waking up can be a painful and difficult process. The past experiences have led them to expect only negative possibilities - the agony of isolation, or harm of some kind.

A brief review of the literature shows that many noted authors agree (a) that waking up is difficult, and (b) that child care practitioners should approach the child sensitively rather than in a militant style. (Bettelheim, 1950; Ginott, 1965; Whittaker, 1969). This paper offers an application of these principles as translated and put into practice by a child care practitioner. It is based on a case experience working in an ego-oriented psychoanalytic model, the Inpatient Service of Children's Psychiatric Hospital at the University

*Requests for reprints should be sent to Dane S. Hughes, Children's Psychiatric Hospital, University of Michigan, 1275 N. Hospital Dr., Ann Arbor, Michigan 48103. 
of Michigan. I believe that it has implications for child care practitioners in various settings with children waking up.

On my unit of 12 children, the wake-up routine includes the following: (a) all children are to be awakened at 7:30 a.m.; (b) children are to be in their rooms until routines are done; (c) before breakfast, beds are to be made and floors picked up; and (d) children are to be dressed.

Within this ward group there is a bedroom shared by two boys whom I will call Scott and Billy, aged 8 and 9 years. They illustrate some morning difficulties particularly well. Scott typically wakes slowly, and he is prone to be irritable, easily distracted, and antagonistic toward his roommate. Billy's bed is nearly always wet or soiled or both, and he awakens in a 'fog" with a very slow cathection to reality. He is unbelievably time consuming in his passive-aggressive style of dealing with routine expectations. These boys feed into each other constantly, setting one another off or egging each other on to conflict with staff and other children.

We had noticed a sharp increase in Scott's verbal, and sometimes physical, attacks on Billy. Also, staff's frustration at Billy's power struggles had increased dramatically. This may have been the outcome of other generalized anxieties, confusions, etc., but the end result was avoiding their need to take immediate responsibility for meeting the expectations of their environment.

\section{Adult as Alter Ego}

It is my theory that such children need to have an adult to perform as the external ego in structuring their reentry into the complex realities that the morning offers. In order to accomplish this, we must understand the child's experience. I have observed that for the child this time is one: (a) of ambivalence about making a commitment to the day; (b) full of anxiety about the multiple demands of the situation; and (c) which often overwhelms the child's ability to break down the task he faces into acceptably sized units. It is crucial for the staff to take responsibility for helping him to accomplish these goals. In this situation he functions as an external ego for the child. He assists the child in progressively stepping through tasks to give the child a feeling of mastery or success in each unit.

The application of this theory involves doing three things during this time. In the engagement phase, it means approaching the child in 
a manner that supports his ambivalent desire to awaken. In the supportive phase, it means using techniques that assure the child that the staff will structure in such a way that he can successfully meet the demands that he faces. Finally, in the task phase, it means breaking down expectations into achievable units.

In dealing with these particular boys, the approach to them in the engagement phase has been to arrive in their rooms at a consistent time and to allow them to feel staff presence before any verbalized demand is placed on them. This is done by opening the curtains, picking up the clothes on the floor, straightening a shelf, etc. There is just enough movement to clearly indicate the child care worker's involvement in their world. As they begin to stir, the opening verbal statement has been something like, "Good morning, boys, it's time to get up." The staff then continues to move about the room for a few minutes and reinforces the commitment to getting up with something like, "It is time to get up right now."

\section{Staff Responsibility}

The emphasis during the supportive phase is on the fact that staff will assume responsibility for limit setting and giving protection. Scott may say, "Phew, old stinky sure smells," to which staff might respond, "Scott, I'll help you get your clothes on. And let's go Billy. I'll get your towel and you get into the shower." What has happened is that the staff has cut off Scott's provocation while supporting him by redirecting his attention to an immediate task with the assurance of staff help and attention. Meanwhile, Billy was feeling embarrassed and overwhelmed by the burden he found himself saddled with before he had even opened his eyes. The staff accepted him where he was and offered support by giving a clear direction of what to do about it along with the offer of help. Normally such suggestions are accepted readily.

Occasionally Billy will require additional support. He might just lay there or get up and wander over to a toy. The temptation for the staff to "reason with him" is great, but it should be avoided. He could immediately turn it into a passive fight with "what?" "huh?" "um," or an active one with "I don't want to." Instead, the staff needs to repeat the direction and take some positive action to reassure Billy that the staff really will support him. This may be done by taking Billy gently but firmly by the arm and walking to the shower room with him, making it clear that the staff really is with 
him and not just offering him empty words. During this time, the staff tries to keep the verbal flow working between himself and each of the children, because the boys are usually still too unintegrated to open any but a destructive dialogue between themselves.

As dressing continues, the task phase is encountered. As adults, we often perceive the idea of making the bed and straightening up somehow as a whole rather than an intricate complex of smaller parts. From the child's view, the opposite is true. Getting dressed is not one operation, but in fact the sum of at least nine separate operations, assuming that all of his clothes are at hand and ready to put on. Bed making is even worse. And picking up can be a lot like untangling the philosopher's knot in half an hour. It's not surprising that so many of our children become frustrated and anxious, facing all this before they even have breakfast.

The staff needs to break these tasks into "chewable pieces," one thing at a time. If Scott is wandering, the direction to put on his clothes is almost meaningless. The direction should be, "Scott, sit down and put on your sock." This seems obvious, but it can get lost by its very simplicity. There is a constant danger of relegating such tasks to the "custodial level" in our thoughts. Getting a child up certainly may not seem to be one of the most exciting therapeutic challenges that the child care worker faces in a day. In a real way, however, this is a critical therapeutic opportunity that deserves our full concentration .

Also, staff often need to overcome such things as having been up too late, not having had coffee yet, and probably having from three to ten youngsters or more to work with. Nonetheless, it is possible to orient oneself toward the child's perception and to work directly at the level that the child is experiencing at the moment. This is the constant challenge of creative child care.

An example of task breakdown is bed making. Bed making consists of putting on a bottom sheet, tucking it in, putting on a top sheet (and the frustration of making the thing lie flat and even all around), tucking it in, putting on a blanket, tucking it in, putting on a spread, tucking it in, holding back the spread, putting on the pillow, and pulling the spread up and tucking it in, a total of 12 operations. There are many other tasks with similar complexity, the point being that any one of these tasks can be broken down in a similar way.

If the staff presents the steps one at a time, the child can experience success at each step and begin to anticipate success at the next step as well. This culminates not only in getting the work done, 
but also with the child feeling a sense of successful mastery at the end. He will then have a reserve of positive feeling about himself to face the rest of the morning. It is obvious that, as with anything in child care, one must be flexible in fitting the breakdown to the child's individual needs, but the principle seems nearly universally applicable to the early morning period. As the treatment of the child progresses, one can expect to do less task breakdown, with the child assuming more of the integrating functions.

The results that we have seen with Scott and Billy have been encouraging. With this approach applied consistently, both boys have fewer hard mornings, get into fewer fights, and generally are in better shape getting to school.

Thus it appears that approaching the morning wake-up time with an eye towards supportive structuring, especially in task breakdown, is a helpful and worthwhile approach. I share this out of my interest in residential treatment, hoping that it will stimulate a valuable cross-fertilization of techniques and approaches applied by different child care practitioners.

\section{References}

Bettelheim, Bruno. Love is not enough. Glencoe, Ill.: Free Press, 1950.

Brown, J. L. "Wake up an emotionally disturbed child with tact, sensitivity, understanding." Involvement, Spring, 1972.

Ginott, Haim G. "The 'good morning'," in Between parent and child. New York: Macmillan, 1965.

Whittaker, J. K. "Managing wakeup behavior," A. E. Trieschman, J. K. Whittaker, \& L. K. Brendtro, in The other 23 hours, Chicago: Aldine, 1969. 